Lepr Rev (2000) 71, 253-255

\title{
Editorial
}

\section{THE GLOBAL ALLIANCE FOR THE ELIMINATION OF LEPROSY (GAEL)}

\section{Introduction}

Significant achievements in the control of the spread of leprosy have been made, particularly in the last 15 years, so much so that in 1991 the 44th World Health Assembly adopted a resolution to eliminate leprosy as a public health problem by the year 2000 . The definition had as its target a prevalence of leprosy of less than 1 per 10,000 population. Obviously, the target will not now be reached. Based on the Assembly resolution, the Nippon Foundation pledged to support and strengthen the initiative through the Sasakawa Memorial Health Foundation (a member of ILEP) and to date have assisted the World Health Organisation with operational funding of over US\$200 million which included a sufficient amount to enable the free supply of MDT drugs until 2000. In 1998/9 when it was clear that the target would not be reached, there was considerable debate about the future of leprosy control, and questions were raised about whom the principal players would be after the year 2000 (cf. Patrick J Brennan, ILA Forum 2nd Series Volume 7, No.1). It was feared that without alternative funding and without funds for drugs the leprosy unit of WHO may disappear. Fortunately, timely discussions with the Nippon Foundation of Japan, and with the pharmaceutical company Novartis, addressed both shortfalls and secured the status quo at WHO for a further 5 years.

\section{GAEL}

Following the concern about the ending of the contract between the Nippon Foundation of Japan and WHO, it was with some relief that we learned that a new funding contract between the two agencies was announced and that there would be a free supply of drugs from Novartis. These offers of support prompted Dr Maria P. Neira, Director. Department of Control, Prevention and Eradication, WHO, Geneva, to start discussions on a 'Global Alliance for the Elimination of Leprosy' with Novartis, the Nippon Foundation, governments of endemic countries DANIDA and ILEP members. The launch of the Alliance took place in Abidjan, Côte d'Ivoire last November and it is hoped that others will join.

Terry Vasey is President of the International Federation of Anti-Leprosy Associations (ILEP) London and Director of The British Leprosy Relief Association (LEPRA) UK. 
Of course, everyone involved in the fight against leprosy welcomed the new initiative to intensify efforts, particularly given that leprosy prevalence still stands around 4.5 per 10,000 in the 12 most endemic countries and that these countries represent about $90 \%$ of the global leprosy problem. Founding members of the Alliance were more than happy to sign up to the new elimination strategy.

The Director General of the World Health Organisation, Dr Gro Harlem Brundtland says that the reasons why the elimination goal is not likely to be met are varied: high prevalence (India, Brazil, Nepal), the intensity of disease transmission (some States in India, Guinea and Madagascar), limited geographical coverage with MDT services (all countries) and in a small number of countries facing civil strife and a damaged health infrastructure (Angola, Mozambique, DR Congo). She adds 'In these countries, elimination will be reached only if special action is taken. In countries having reached elimination recently, it is essential to ensure that core control activities are sustained, and the leprosy situation is closely monitored for a number of years before confirming that the disease has been eliminated' (see the GAEL website at: http://users.breathemail.net/steve.lyons/gael/index.htm).

The WHO elimination strategy is based on the widespread implementation of MDT and the Global Alliance is a partnership dedicated to ensuring that all leprosy patients, wherever they may live, and however poor, have free and equal access to the most modern treatment available. The robustness of this form of treatment enables paramedics, nurses and community leaders to treat the disease wherever it occurs - in the city or in the village.

The Director General notes that India, Indonesia and Myanmar account for $70 \%$ of all the cases in the world. In Africa, the second most affected area, the situation is more difficult for the moment. The AIDS epidemic, the resurgence of the major tropical diseases, weaknesses in health inf rastructure, social unrest and armed conflict make leprosy elimination seem like a luxury, an impracticable one at that. The situation remains worrying in Latin America. Brazil is particularly badly affected, accounting for over $80 \%$ of cases in that continent. In Central and Eastern Europe, there are sporadic cases; it is impossible at present to tell how many such cases go unreported. WHO and its partners are dedicated to ensuring that all leprosy patients, wherever they may live, and however poor, have free and equal access to the most modern treatment available.

Since the launch of the Alliance, several meetings have taken place to discuss the intensified strategy and a Technical Advisory Team has been formed. Health Education and Training Materials have been designed and are being tested. Several countries have set up national and/or local Task Forces bringing together all those engaged in the fight against the disease and plans have been drawn up in many countries. The first global review of the Alliance is planned to take place in India (the first Chair of GAEL) in January 2001.

In India the five endemic states of Bihar, Madyha Pradesh, Orissa, Uttar Pradesh, and West Bengal contribute $70 \%$ of the total patient load of the country and so in coming years there will be increasing focus on these areas. The intensified strategy there is directly linked to the second phase of World Bank funding to the National Leprosy Elimination Programme. The plan is to consolidate achievements in leprosy elimination and will focus on integration of the (largely vertical) programme into the general health service. This integration is planned to take place within the 3-year period of the Bank's funding. It is likely that some states will not be in a position to effect integration until almost the end of the time period. An adequate surveillance system to prevent the resurgence of the disease is also extremely important to the success of the future strategy.

ILEP members, as part of GAEL, recognize the need to engage constructively in the 
broadening of effective alliances. In the Indian context therefore it will be of vital importance over the next 3 years that we are proactively involved in the government's leprosy work being funded by the World Bank. The importance of the role of NGOs including ILEP members is already clearly recognized by the World Bank. To quote Mr Peter Heywood, Principal Public Health Specialist, World Bank, New Delhi, 'The project envisages a significant input from NGOs both international and local. The significant contribution of international and national partners in leprosy control is known. It is expected that NGOs contracted under the project would take up substantial proportions of the activities under each unit. The relationship between the government and non-government organizations would be clearly defined and would be assessed by an agreed set of performance criteria.",

Further, at a state level he goes on to say 'all inputs for leprosy control by all organizations would have to come together in a cohesive manner for best results to be achieved, and be reflected in the state and central government's plans for elimination of leprosy (by 2003!).'

Keeping in mind that the GoI is the chair of GAEL and that the bulk of our (ILEP's) work is there, the need to actively engage in such broader alliances is crucial if our work is to continue to be effective in ensuring every person affected by leprosy receives the effective treatment and care they require.

\section{Conclusion}

We have set ourselves a tough target and if we are to be successful we must ensure that all involved keep leprosy near the top of the agenda and wherever possible attract the involvement of new partners. What is imperative is that we all recognise the contribution of each other and avoid duplication. We must ensure that resources are used in the most efficient manner whilst recognizing that for members of the Alliance, the elimination target is not our only concern. WHO provides technical assistance on many diseases and conditions, Health Ministers are concerned with the general health of their population, donors may support other causes and for ILEP members, elimination is only part of our overall goal. Even after the target is reached, there will continue to be new cases of leprosy, and the number of people who have been affected by the disease continues to grow. ILEP is pledged to fight for a world without leprosy and members will continue to strive for this after the target date is reached as many who are affected by the disease will still be with us.

LEPRA, Fairfax House,

TERRY VASEY

Causton Road,

Colchester CO1 1PU, UK 